\title{
Para una aproximación a la (r)evolución del discurso político latinoamericano desde Fidel Castro hasta Rafael Correa
}

por Irina Bajini

A Ernesto, la vida misma

Estas observaciones sobre la forma y el estilo del actual discurso político de los líderes de la izquierda latinoamericana - de Fidel Castro a Rafael Correa pasando por Hugo Chávez, Evo Morales, Luiz Inácio Lula da Silva y el menos locuaz Fernando Lugo' - nacen de una experiencia concreta, ya que gracias a un vínculo profesional con el ESTI (Equipo de Servicios de Traductores e Intérpretes del Consejo de Ministros de la República de (uba) tuve la oportunidad durante años - máxime entre 1995 y 2002 - de traducir discursos oficiales, así come de participar a eventos políticos internacionales en calidad de traductora consecutiva y simultánea. De ahí, que cuando en el 2003 fui invitada a participar en la Jornada de Traducción por el XXX aniversario del ESTI (La Habana, 20 de octubre), me atreví a presentar una ponencia titulada "Traducir al comandante: lengua y retórica del discurso político en Cuba", en donde, a partir de mi experiencia personal, intentaba demostrar como la teoría puede auxiliar a la práctica, y viceversa, a partir de la consideración que reflexionar seriamente sobre el trabajo del traductor y la estructura profunda de los textos objeto de traducción es un trabajo imprescindible y una inversión para el futuro de los profesionales de este sector. Para lograr este objetivo tuve que por un lado analizar la estructura de los discursos, buscar

${ }^{1}$ Para reducir los riesgos de dispersión, he decidido excluir de mi análisis los discursos de la ex presidenta chilena Bachelet así como del neoelecto uruguayo José Mujica, dejando también para otra ocasión la observación del discurso político argentino del los Kirchner, todos merecedores de un espacio y un tiempo más adecuados. 


\section{Altre Modernità / Otras Modernidades / Autres Modernités / Other Modernities}

Università degli Studi di Milano - Facoltà di Lettere e Filosofia

Dipartimento di Scienze del Linguaggio e Letterature Straniere Comparate - Sezione di Studi Culturali

sus fuentes, individuar las herramientas retóricas, los niveles de comunicación y el estilo, y por otro, reflexionar sobre el proceso de la traducción, es decir sobre lo que significa poner un texto en otro idioma, considerando el discurso político no como un simple conjunto de cuartillas, sino como un género literario autónomo, que responde a determinadas leyes y modelos.

Hoy en día, sigo creyendo que para acercarse al discurso político hay que enfocar el tema del discurso como estructura y proceso según la teoría y el análisis del texto y la conversación elaborados por Teun A. Van Dijk².

El análisis contemporáneo del discurso ha recorrido un largo camino desde los primeros estudios lingüísticos de los pronombres y la coherencia semántica, las primeras observaciones de la toma de turnos en la conversación o los estudios etnográficos acerca de "la manera de hablar" en diversas culturas, y con el tiempo se ha producido una inevitable especialización. Según la psicolingüística, los estudios del discurso demuestran que la utilización del lenguaje se plasma en la interacción social discursiva, mientras que para las ciencias sociales el análisis del discurso subraya la necesidad de estudiar las instituciones sociales y políticas, la relaciones de grupo y su expresión o realización en el discurso como uso del lenguaje, comunicación e interacción.

En esta misma línea, los analistas del discurso admiten que el discurso es una forma de uso del lenguaje; sin embargo, a este concepto incluyen otros componentes esenciales, a saber quien utiliza el lenguaje, como lo utiliza, por qué y cuando lo hace. En otras palabras, las personas utilizan el lenguaje para comunicar ideas o expresar emociones y lo hacen como parte de sucesos sociales más complejos, así que, por ejemplo, el discurso político no significa solo un texto oral, sino una persona hablando en un contexto colectivo. Por eso se dice que el discurso es una interacción verbal y por esta razón nuestros analistas estudian la conversación y el texto en su contexto.

Para aportar una descripción estructural del discurso, podemos comenzar por considerarlo como una secuencia de oraciones dispuestas en un orden específico y establecer las diversas relaciones y condiciones que definen la "discursividad" de secuencias de oraciones, recordando que tampoco la estructura formal de las oraciones en el discurso es independiente del resto del discurso y que en esta análisis no se puede omitir el aspecto visual.

Para la semiótica es notorio que un análisis de las dimensiones visuales del discurso resulta indispensable, especialmente en tiempos de comunicación multimedial. Efectivamente, en el discurso hablado las palabras van acompañadas por diversos tipos de actividad no verbal, como los gestos, las expresiones faciales, la posición del cuerpo, el aplauso y la risa. Todos estos elementos requieren un análisis del papel que juegan en el suceso de comunicación como totalidad.

${ }^{2}$ Me refiero sobre todo a la versión española de El discurso como estructura y proceso: introducción multidisciplinaria, e Ideología. Un enfoque multidisciplinario, así como a diferentes artículos presentes en la página web del autor (<http://www.discursos.org/>). 


\section{Altre Modernità / Otras Modernidades / Autres Modernités / Other Modernities}

Università degli Studi di Milano - Facoltà di Lettere e Filosofia

Dipartimento di Scienze del Linguaggio e Letterature Straniere Comparate - Sezione di Studi Culturali

Cada discurso, además, se basa en tópicos y temas, que constituyen sus sentidos globales, definiendo su coherencia o macrocoherencia. Finalmente, es importante reflexionar sobre el estilo, por lo cual, según el contexto, las mismas ideas se expresan con adjetivos y términos diferentes.

En el caso específico del discurso político un aspecto vinculado al análisis estilístico es la dimensión retórica, que puede acompañarse a cierta conciente o no del todo conciente estrategia de mistificación de la realidad. Y si creemos, al igual que Eliseo Veron (1987) que todo discurso político es una producción discursiva explícitamente articulada a las instituciones del Estado, es natural que el hablante político, usualmente en una situación de conflicto con sus adversarios, procure legitimarse por medio del discurso, ya que la legitimación, como señala Van Dijk (1999) es una función general del discurso que tiene particular importancia en la esfera política: los políticos explican y defienden su conducta y posiciones ante las objeciones efectivas o posibles de sus oponentes y la legitimación del hablante es particularmente necesaria en situaciones de ejercicio del poder constitucional. Por cierto, el hablante político construye una versión positiva de si mismo, que suele contraponerse a la negativa del otro. Entre otros recursos lingüísticos, los elementos de valoración positiva y negativa cumplen esta función caracterizadora de posiciones opuestas. Por eso son frecuentes los procesos de antinomia.

Los críticos retóricos consideran los textos como unidades pragmáticas: un texto retórico responde a ciertos temas o problemas propios de una sociedad, o interactúa con ellos o produce cierta acción o cambio en el mundo. A partir de tres conceptos, es decir la exigencia (el contexto histórico, es decir "el decoro" gorgiano), la audiencia (que no siempre es el auditorio que tiene físicamente cerca sino el auditorio implícito) y la credibilidad del orador (el ethos aristotélico), hoy en día se ha incrementado la apreciación de la importancia histórica de los discursos públicos, sus efectos políticos, su funcionamiento interno y estructura, así como el modo por el cual la retórica invita a la construcción o reconstrucción de sucesos y fenómenos.

En el caso del discurso político cubano, la lección ciceroniana es muy evidente y se explica por la cultura clásica de Fidel Castro, por sus estudios en colegios jesuitas y por su carrera de derecho y su experiencia de abogado. Es a partir de un conocimiento directo y de un serio estudio de algunos filósofos clásicos y cristianos (Platón, Aristóteles y San Agustín en primer lugar) de la Biblia y del Evangelio, de José Martí y en medida menor de Carlos Marx, que nuestro autor va estructurando sus discursos, va preparando y almacenando su herramienta retórica y sus citas bien escogidas, que utiliza y recuerda según la mnemotécnica clásica y cristiana.

Los críticos retóricos distinguen a menudo entre un orador y la persona creada en el texto retórico, tal como en la crítica literaria es común distinguir entre el autor de una obra literaria y la persona ficticia del autor creada en esa obra. Y es natural que un líder como Fidel, tras más de cincuenta años de actividad oratoria haya llegado a tener mucha flexibilidad para construir su persona retórica y para crear diferentes tipologías 


\section{Altre Modernità / Otras Modernidades / Autres Modernités / Other Modernities}

Università degli Studi di Milano - Facoltà di Lettere e Filosofia

Dipartimento di Scienze del Linguaggio e Letterature Straniere Comparate - Sezione di Studi Culturali

de discurso manteniéndose coherente a ellas ${ }^{3}$. En este sentido, ninguno de los demás oradores latinoamericanos por mí considerados podría competir con el abogado Castro relativamente a experiencia política, formación académica y curiosidad de lector omnívoro. Correa, que es el más joven y preparado, es un economista con doctorado en Estados Unidos, Fernando Lugo es un ex obispo sin grandes estudios teológicos, Hugo Chávez e Inácio Lula da Silva, orgullosos de su origen proletario, se han formado, por así decir, en la escuela de la vida.

Si gran interés hay que poner en el diseño del discurso, una no menor atención debe dedicarse a su contenido lingüístico.

En su artículo sobre "El discurso político-propagandístico en el español de Cuba" (1996-1997) Gisela Cárdenas subrayaba que el vocabulario empleado en el discurso político no presenta peculiaridades semánticas propias que permitan trazar una línea divisoria entre éste y el léxico común, como sucede con la terminología especializada. Los vocablos son, en su mayoría, polifuncionales, se usan tanto en textos políticos como en el habla corriente, y tienen un carácter público, masivo. Esta casi indiferenciación se debe a que el significado de las voces políticas tienen contornos difusos y precisamente esta imprecisión semántica origina su plurivalencia.

Por otra parte, la acepción de los vocablos políticos es por regla general muy dinámica, ya que estos se prestan con mucha facilidad para designar situaciones nuevas creadas por condicionamientos ambientales. Además, su significado varía de una época a otra y también de acuerdo con los sistemas conceptuales políticoideológicos que existen en un momento dado.

Para Gisela Cárdenas el vocabulario político - pese a su polifuncionalidad - es un subsistema terminológico que consta de dos grandes componentes:

a) los conceptos que aparecen, sobre todo, en los contextos políticos y económicos y que tienen un acento marcadamente político social por sus relaciones contextuales;

b) los conceptos específicamente políticos.

El vocabulario empleado es eminentemente neológico, desde el punto de vista formal y semántico. Esto quiere decir que a menudo nacen neologismos o determinada palabra adquiere un significado nuevo.

Sin embargo, el discurso político es poco creativo, ya que abundan los estereotipos tanto en el vocabulario como en la sintaxis y en la organización textual. Se trata de combinaciones usuales, sintagmas recurrentes, lo que Coseriu (1977) llama "Discurso repetido".

Es indudable que el empleo previo de estas expresiones esta supeditado a las normas de comprensión comunes a un círculo muy amplio de receptores. De aquí que

\footnotetext{
${ }^{3}$ Aunque no cabe duda de que todos los discursos nacionales del líder máximo están marcados por un estilo inconfundible y coherente a lo largo de muchas décadas, mezcla de brillante despliegue de herramientas retóricas, habilidad histriónica y sensibilidad empática con el público, creo personalmente que uno de sus discursos más bellos e inspirados es el de bienvenida al papa Juan Pablo II (21 de enero de 1998), pronunciado en la cumbre de su parábola humana y política.
} 


\section{Altre Modernità / Otras Modernidades / Autres Modernités / Other Modernities}

Università degli Studi di Milano - Facoltà di Lettere e Filosofia

Dipartimento di Scienze del Linguaggio e Letterature Straniere Comparate - Sezione di Studi Culturali

se establezca, en el aspecto connotativo, una correspondencia entre la intención del hablante, el efecto real de la comunicación y la norma de expectación del receptor de dichos esquemas formularios.

Desde el punto de vista funcional, las colocaciones estereotipadas se comportan en los textos políticos de manera análoga a los términos. Como estas expresiones designan fenómenos similares, llegan a adquirir una carga semántica especial, se terminologizan. En este modo el estereotipo permite generalizar y uniformar el flujo de información. Su frecuente repetición en el texto se toma como algo natural y regular.

Algunas expresiones estereotipadas se ponen de moda y encuentran gran repercusión en los textos políticos de propaganda; a pesar de esto, son muchos los lingüistas que condenan enérgicamente el uso de experiencias estereotipadas por considerarlas al polo opuesto de la creatividad, pero es cierto que para valorarlas hay que basarse en sus especificaciones comunicativo-funcionales.

Finalmente, hace doce años Gisela Cárdenas subrayaba que en el discurso político cubano, a raíz de una unidad política y una ideología científica común, una parte mayoritaria de la población defendía los mismos valores, y esto favorecería grandes concordancias tanto en la denotación como en la connotación del vocabulario político, así como también en la apreciación y toma de posición en lo que se refiere a sucesos políticos o sociales, internos o acaecidos en al arena internacional.

Es evidente que hoy en día, a pesar del silencio público del gran modelo cubano ${ }^{4}$ mucho perdura de su lección en la estructura de los discursos presidenciales de Chávez, Morales, Lula, Lugo y Correa; sin embargo, mi hipótesis es que a partir del líder venezolano - aunque el alumno a nivel macroscópico imite al maestro hasta en los gestos y en las muecas - haya habido una evolución en la forma del discurso perfectamente coherente con las exigencias de su contenido y del contexto político en que se produce.

Empezaré un primer cotejo de los discursos basándome en los indicadores lingüísticos y sociológicos que Cárdenas (1996/1997: 19-20) sugiere como característicos en el discurso político-propagandístico:

1) Uso de expresiones léxicas y combinaciones de palabras con una connotación de grandiosidad, así como de adjetivos en grado comparativo y superlativo

CASTRO: "La Revolución emerge más vigorosa frente a cada golpe y cada agresión, se profundiza, se hace más conciente, más fuerte" (1976: 28)

CHÁVEZ: "Después de esta jornada memorable, histórica, imborrable para siempre jamás" (2002: 10/12)

${ }^{4}$ Es notorio que Fidel Castro Ruz, tras haber dimitido de su cargo de presidente del Consejo de Estado y Comandante en Jefe por razones de salud, ha dejado de hablar en público desde el 26 de julio de 2006, transformando sus discursos en "reflexiones" escritas, una tipología textual bastante original que merecería una específica atención. 


\section{Altre Modernità / Otras Modernidades / Autres Modernités / Other Modernities}

Università degli Studi di Milano - Facoltà di Lettere e Filosofia Dipartimento di Scienze del Linguaggio e Letterature Straniere Comparate - Sezione di Studi Culturali

LULA: "E' hora de acender a pira olímpica em um país tropical, na mais linda e maravilhosa cidade: o Rio de Janeiro" (2009: 02/11).

MORALES: "Este compromiso, en lo más sagrado de Tiahuanacu..." (2006:21/01)

LUGO: "la digna estirpe paraguaya” (2008:15/08)

CORREA: “... vamos a sostener este despertar gigante, sublime..." (2009)

Nota: en todos los discursos aparece este recurso, más abundante en los de Chávez y Morales.

2) Uso de marcadores lingüisticos que dan un tono de familiaridad al mensaje, de comunicación camaraderil

CASTRO: "Yo les pedí a los colegas - no los llamo compañeros porque no quiero aparecer tan extremista de izquierda como el presidente del Banco Mundial..."(1999: 109)

ChÁvez: "Yahya Jammeh, te espero allá en Margarita. Presidente de Gambia... Ponte el aparatico aquí, ... ok. Yahya. ¡Viva el Africa!" (2009)

LULA: "Muito obrigado, gente!" (2006).

MoRALES: "Héctor Arce, nuestro abogado, me recordaba, antes de salir acá a esta sesión, y me dice, Evo, un día como hoy, 22 de enero, te expulsaron del Congreso Nacional (2006:22/01)

LUGO: "Vos me diste (...) Vos, con una sonrisa fuiste a las urnas el 20..." (2008: 15/08)

CORREA: “Compañeras, compañeros..." (2009)

Nota: quién más se resiste al inciso camaraderil es Correa. A quién se le va (concientemente) la mano es a Chávez.

3) Empleo de enunciados performativos en los cuales el verbo designa la acción y al mismo tiempo la reproduce en el momento de la enunciación

CASTRO: "¡Sigamos adelante, sigamos trabajando, sigamos sembrando, sigamos enseñando!" (1961: 8/11)

ChÁvez: "Pidamos a Dios por los que murieron durante las jornadas de abril, pidamos a Dios por la vida de todos..." (2002: 13/10) 


\section{Altre Modernità / Otras Modernidades / Autres Modernités / Other Modernities}

Università degli Studi di Milano - Facoltà di Lettere e Filosofia Dipartimento di Scienze del Linguaggio e Letterature Straniere Comparate - Sezione di Studi Culturali

LULA: "Temos de retomar, com vigor, nossa coordenaçâo macroeconômica" (2006).

MoRAlEs: "Apostemos desde ahora para esa Asamblea Constituyente" (2006: 22/01)

LUGO: "No dejaremos que nadie muera de hambre..." (15/08)

CORREA: "...recuerden que las prioridades son claras y no deben descuidar a sus seres queridos... "(2009)

Nota: es un recurso moderadamente usado por todos.

4) Empleo de consignas para atraer la atención y crear un estado anímico propicio en los receptores

CASTRO: “iPatria o muerte!, ¡Ya vencimos, y seguiremos venciendo! (1961: 22/12)

CHÁVEZ: “¡Viva la Revolución Bolivariana! (2002:13/10)

LULA: "Viva o povo brasileiro"! (2003)

MORALES: “¡Gloria a los mártires por la liberación! (2006: 22/01)

LUGO: “¡Despierta Paraguay! " (2008: 15/08)

CORREA: "Por la Patria, tierra sagrada, hasta la victoria siempre!" (2009)

Nota: Los más tibios en emplear consignas son Lula y Lugo. Chávez, además emplearlas en abundancia, estimula una participación activa del público que incluye ocasionalmente la celebración de una "ola", fenómeno que normalmente ocurre entre los asistentes de eventos deportivos: "Vamos a ver, preparados para la ola. Cuando yo baje la boina comienza la ola de aquí para allá. A la una, a las dos y a las tres. ¡Allá va la ola!" (2002:13/10).

5) Empleo de fraseologismos, construcciones sintácticas y vocablos propios del estilo coloquial

CASTRO: "...mañana tendrán ya salsa para el arroz con mango...

CHÁVEZ: "¿Ustedes han visto un juego de béisbol que no, hay que pitchear a medio brazo? ¡A brazo completo! ¡Ah!, Lage fue el que dijo que era a medio brazo. Alduro y sin guante, y bateando con la mano" (2007)

LULA: "Deus, quando fez o ser humano, ele deu uma boca para a gente falar..." (2009, 14/12). 


\section{Altre Modernità / Otras Modernidades / Autres Modernités / Other Modernities}

Università degli Studi di Milano - Facoltà di Lettere e Filosofia Dipartimento di Scienze del Linguaggio e Letterature Straniere Comparate - Sezione di Studi Culturali

MORALES: "Necesitamos un golpe de timón de fondo y a nivel mundial..." ()

LUGO: "borraste de un boletazo toda la mala onda..." (2008: 15/08)

CORREA: "Ya nos fregamos" (2007)

Nota: Los más reacios al empleo de un estilo coloquial son sin duda Correa y Morales. Chávez por lo contrario, utiliza a menudo regionalismos y palabras y metáforas del lenguaje deportivo (sobre todo del béisbol). Castro, a pesar de identificarse programáticamente con su pueblo, nunca emplea vulgarismos. En cambio Lula, que "fala a língua do povo, mas muito melhor do que a maioria do povo" (Machado, 2003) de vez en cuando, y creo yo que concientemente, suelta un mala palabra ("Eu quero saber se o povo está na merda e eu quero tirar o povo da merda em que ele se encontra")

6) Utilización de nombres de hechos y personajes históricos para designar sucesos actuales con lo cual se acentúa la capacidad de lucha

CASTRO: "No habrá que explicar mucho más a los cubanos las razones del Juramento de Baraguá..."

CHÁvEZ: "Por eso traemos aquí otra propuesta, anclada en la Carta de Jamaica, que escribió Simón Bolívar, el gran Libertador del Sur...." (2005)

LULA: "Zumbi dos Palmares é um herói brasileiro..." (2003).

MORALES: "... podemos seguir recordando como nuestros antepasados lucharon: Túpac Katari para restaurar el Tahuantinsuyo, Simón Bolívar que lucho por esa patria grande, Che Guevara que luchó por un nuevo mundo en igualdad." (2006: 22/01)

Lugo: "Quisiéramos que Rafael Barret con su 'dolor Paraguayo' y Augusto Roa Bastos con su 'isla rodeada de tierra' descansen ya en la certeza de una herencia redimida" (18/08)

CORREA: "Esa fue la concepción extraordinaria del Viejo Luchador Eloy Alfaro Delgado, general de hombres libres" (2009)

Nota: Castro es el más generoso en evocaciones históricas y Lula es quien menos acude a este tipo de recurso. En los discursos de Chávez campea, ça va sans dire, la figura de Simón Bolívar. Alrededor del cual se construye un proyecto revolucionario nacional de raíz independentista y proyección latinoamericanista. 


\section{Altre Modernità / Otras Modernidades / Autres Modernités / Other Modernities}

Università degli Studi di Milano - Facoltà di Lettere e Filosofia Dipartimento di Scienze del Linguaggio e Letterature Straniere Comparate - Sezione di Studi Culturali

\section{7) Empleo de términos y metáforas de la esfera militar}

CASTRO: "... trinchera de ideas e inexpugnable fortaleza frente al enemigo..." (2001)

CHÁVEZ: "... no hay posibilidad de defensa sin ataque, no hay posibilidad de ganar una batalla si no se tiene un plan de ataque, nadie gana una batalla de defensa en defensa... (2002: 13/10)

LULA: "A história do Brasil é rica em exemplos de resistência e luta..." (2003).

MORALES: "¿Para qué las guerras?" (2006: 22/01)

LUGO: "Y la guerra es la cosa que se hace, también la paz es una cosa que hay que hacer.." (2009)

CORREA: "... hacer del pensamiento una trinchera de solidaridad" (2009)

Nota: Es evidente la presencia de un frente metafóricamente belicista (Castro y Chávez) y otro pacifista desde el punto de vista lingüístico (Correa, Lula) al igual que ideológico (Morales, Lugo).

Para identificar las características significativas de un texto, los críticos hacen hincapié en tres aspectos: la estructura y temporalidad, la argumentación, que utiliza el lenguaje para justificar o refutar un punto de vista con el propósito de asegurar un acuerdo en las ideas, la metáfora y la iconicidad, que es el uso estético de las palabras, pero sólo aparentemente ornamental, porque puede transmitir un mensaje, o al menos reforzar un mensaje, al auditorio.

El lenguaje indirecto es también un recurso abundante en el discurso político, mientras que Chilton y Schaffner (2002) hablan de discurso de coerción, que busca su aceptación por medio de un lenguaje de solidaridad, suavizado, indirecto y alusivo. Este se relaciona también con la construcción positiva del hablante político, para quien puede resultar más conveniente un ejercicio disimulado del poder. Las formas indirectas de referencia también ocurren en el discurso de la resistencia como parte de una estrategia de protección.

Otro uso del lenguaje indirecto se relaciona con el tratamiento de temas problemáticos. Un asunto problemático puede producir una expansión de formas significantes que construyen la significación desde varios ángulos. El proceso puede ser muy rico y tiene que ver desde luego con la metáfora.

Resumiendo, los rasgos que permiten tipologizar el discurso político propagandístico desde el punto de vista funcional son:

- una determinada organización del material lingüístico, que demuestra lo específico de este tipo de comunicación;

- la orientación pragmática de los recursos lingüísticos empleados; 


\section{Altre Modernità / Otras Modernidades / Autres Modernités / Other Modernities}

Università degli Studi di Milano - Facoltà di Lettere e Filosofia Dipartimento di Scienze del Linguaggio e Letterature Straniere Comparate - Sezione di Studi Culturali

- el carácter específico de la situación comunicativa, determinada por el conjunto de condiciones lingüísticas y extralingüísticas en las cuales se desarrolla la propaganda y la agitación.

Por eso, a todos los indicadores arriba mencionados voy a añadir otros cinco, es decir:

\section{8) Empleo de términos y metáforas de la esfera utópica}

CASTRO: "Somos un pueblo construyendo futuro" (1961: 14/5)

CHÁvEZ: "hacer realidad los sueños de todos" (2002: 13/10)

LULA: "a nossa esperança é maior do que o nosso medo" (2003)

Morales: "Juntos desde el Parlamento cambiaremos nuestra historia" (2006: 15/08)

LUGO: "despertar al Paraguay real, histórico e incontenible en su rumbo hacia la alborada de felicidad tan postergada" (2008: 15/08)

Correa: "Mi sueño es ver (...) una Patria sin opulencia, pero digna y feliz" (2007: 15/01)

Nota: El sueño de Correa es de inspiración norteamericana (Martin Luther King). Castro y Lula son los menos utópicos, el primero porque habla como protagonista de una revolución hecha, el segundo porque - a diferencia de Chávez y Correa que invocan la revolución bolivariana y la revolución ciudadana - no persigue ninguna revolución.

9) fórmulas de apertura y clausura con las cuales el orador se dirige a su público nacional

CASTRO: a - compatriotas (1959 y de vez en cuando); compañeras y compañeros (constante desde 1960)

c - Patria o muerte, venceremos (desde 1960)

CHÁVEZ: a -¿Qué es lo que ustedes están pidiendo? ¿Cómo? ¿Está el ministro Vargas por ahí?

c - ¡Viva el pueblo! ¡Viva la patria! ¡Viva la revolución! ¡Viva la paz! ¡Un abrazo a toda Venezuela, hermanos! (2002:13/10)

LULA: a - meus compañeiros e minhas companheiras.. excelentíssimos señores... trabalhadores e trabalhadoras do meu Brasil

c - muito obrigado, meus companheiros, e até amanhã (2003:010/01) 


\title{
Altre Modernità / Otras Modernidades / Autres Modernités / Other Modernities
}

Università degli Studi di Milano - Facoltà di Lettere e Filosofia Dipartimento di Scienze del Linguaggio e Letterature Straniere Comparate - Sezione di Studi Culturali

\author{
MORALES: a - hermanas y hermanos (2006: 22/01) \\ c - muchísimas gracias (2007: 24/09) \\ LUGO: a - Paraguayos y paraguayas, compatriotas de América y ciudadanos \\ del Mundo. \\ c - gracias a todos (2008: 15/08)
CORREA: a - queridos compatriotas
c - Dios bendiga al pueblo ecuatoriano...jApunchik ñukanchik llaktata bediciachun! (2009: 10/08)

Nota: Castro ha mantenido durante cuarenta y seis años la misma fórmula sobria y lapidaria - de apertura y clausura en perfecta coherencia con las consignas ideológicas de la Revolución cubana. Lula, Morales y Lugo, en cambio, optan por un marco tímido y respetuoso que no asuste a sus oyentes. Chávez, trasgrediendo del modelo genérico (como bien demuestra Narvaja de Arnoux), sorprende a su público con coups de théâtre y se despide con una exhuberante declaración patriótica. Correa, finalmente, en el marco de un discurso siempre elegante y pulido, logra introducir con extrema naturalidad un elemento lingüístico de por sí - tratándose de quechua altamente transgresor. También Morales rompe una vez el esquema, y nada menos que en su "Discurso de posesión" (2006: 22/01), pero a través de una declaración transparente, directa e ingenua, en el sentido que para nada "diplomática":

\begin{abstract}
Para recordar a nuestro antepasados (...) pido un minuto de silencio para Manco Inca, Túpac Katari, Túpac Amaru, Bartolino Sisa, Zárate Villca, Atihuaiqui Tumpa, Andrés Ibáñez, Che Guevara, Marcelo Quiroga Santa Cruz, Luis Espinal, a muchos de mis hermanos caídos, cocaleros de la zona del trópico de Cochabamba, por lo hermanos caídos en defensa del pueblo alteño, de los mineros, de miles, de millones de seres humanos que han caído en toda América...
\end{abstract}

10) presencia de dialogismo, digresiones o citas

CASTRO: “Caramba!, qué lástima que no tengo aquí... ¡Ah!, Carlitos, por ahí había el otro día uno de los papeles donde estaban todos los organismos que creó el gobierno de Estados Unidos, después del atentado, porque no se sabe los cientos de miles que cuesta todo lo creado por ellos, y, realmente, nosotros les podemos ofrecer información gratuita, lógica y elemental. A nosotros no nos ha costado más que unos papelitos, leer unos periódicos" (2005)

CHÁVEZ: "Hace poco se reunieron en un barco, ¿supieron eso? Los jefes del G8, creo, decidieron reunirse en un barco en alta mar. Sí, yo lo vi en la prensa y dije: bueno, es el último recurso, en la mitad del Atlántico; en la mitad del Atlántico o del Pacífico, en un barco porque ya nadie se atreve a hacer Cumbre de esas. Aquí 


\section{Altre Modernità / Otras Modernidades / Autres Modernités / Other Modernities}

Università degli Studi di Milano - Facoltà di Lettere e Filosofia Dipartimento di Scienze del Linguaggio e Letterature Straniere Comparate - Sezione di Studi Culturali

en Venezuela, Dios nos libre de una cumbre de esas. Cumbre sociales sí. Venezuela se abre para estas Cumbres Sociales" (2001)

LULA: "Eu quero terminar agradecendo a essa companheira, que hoje -eu quero fazer uma homenagem porque hoje nós estamos aqui-, Marisa, [está] muito bonita, toda elegante, ao lado do marido dela com essa faixa, que nós sonhamos tanto tempo" (2003)

MORALES: "Perdónenme compañeros, no estoy acostumbrado hablar tanto, no piensen que Fidel o Chávez me están contagiando, estamos en la obligación de decir la verdad sobre nuestra Bolivia, y para no confundirme primera vez preparé una chanchulla, me está fallando la chanchulla, perdón.

Nota: Ni Lugo ni Correa suelen hacer uso de citas. Raras son también las digresiones en los discursos de Lula y Morales. En el caso de Chávez podemos seguramente hablar de dialogismo generalizado expreso (Narvaja de Arnoux), así como en el caso de Castro, que sin embargo se mantiene siempre en el cauce de la retórica clásica.

\section{1) uso de otros idiomas}

CASTRO: solo español

CHÁVEZ: "Querido Fidel, allá donde estás. How are you”? (2007)

LULA: solo portugués

MORALES: "'Quiero agradecer a nuestros antepasados por dejarnos la mejor herencia para mí y para los pueblos del mundo. Ama Sua, Ama Llulla, Ama Quella: No robar, no mentir, ni ser flojo, hermanas y hermanos...iQue vivan los procesos revolucionarios del mundo! ¡Jallalla Kollasuyu marka!"

LUGO: Muchas gracias, buen día joaite. Estimados ministras... Pa'i Oliva. Veo al pa'i Pepe también por ahí $(2009,19 / 12)$

“Ha ndaha'éiva la ndaipóriva la plata. Ha Itaipu oreko la plata, 20, 30, 40 millones de dólares" (2010, 19/02)

CORREA: "Dios bendiga al pueblo ecuatoriano. Mashikuna Ñami punchaka chayashka Shuk shikan, mushk llaktata shaychinaka usharinmari Nukanchik gobiernoka tukuy runakunapa gobiernomi kanka. Pi mana ñukanchikta atinkakunachu (2007: 15/01)

Nota: hay una evidente línea de demarcación entre Castro, Chávez y Lula - que por razones históricas, como en el caso del líder cubano, o bien culturales y 


\section{Altre Modernità / Otras Modernidades / Autres Modernités / Other Modernities}

Università degli Studi di Milano - Facoltà di Lettere e Filosofia

Dipartimento di Scienze del Linguaggio e Letterature Straniere Comparate - Sezione di Studi Culturali

biográficas, no problematizan el uso de la lengua española o portuguesa ni ven la cuestión de la lengua como políticamente urgente - y los otros tres. Para Lugo, el empleo - por cierto ni constante ni absoluto - del guaraní en discursos de tema nacional o regional es casi que obligado por razones institucionales, siendo el guaraní lengua cooficial del Paraguay y hablado por casi la totalidad de la población del país; de gran significado simbólico y fuerte valor político es, en cambio, la elección de la lengua quechua para cerrar nada menos que un discurso de posesión (Correa) o las citas en quechua y aymara que Morales empleó durante la reciente ceremonia andina en Tiwanacu ( 21 de febrero de 2010) donde fue ratificado Guía Moral de las naciones originarias de América Latina 5 .

\section{2) referencias religiosas}

CASTRO: "para luchar contra la explotación no es obstáculos que uno sea creyente, tenga una religión, sea cristiano, sea de cualquier religión, y el otro sea marxista, el otro tenga su fe en la filosofía marxista... la Revolución tiene que ser, ante todo, $f e$ en sus propias ideas... porque tenemos $f e$ en nuestras ideas y tenemos fe en nuestro pueblo".

CHÁVEZ: "iPidámosle a Dios Padre Creador y pidámosle al Cristo Redentor de los pueblos que nos siga acompañando por este camino que es el camino que señaló Jesús de Nazaret, el camino, el reino de los cielos pero en la tierra, el camino de la vida...jDios guarde a Venezuela para siempre!... ¡Dios guarde al pueblo bolivariano para siempre! $(2002,13 / 10)$

LULA: "Nesse momento solene em que nos reunimos diante da nação e sob o olhar de Deus, para presenciar e celebrar com ardor cívico e cristão a sanção da lei que institui o Dia Nacional da Marcha Para Jesus, brilha no céu da pátria a luz da nossa fé" (2009: 06/09)

MoRAles: "Gracias (...) a mis padres -que en paz descansen (...) a Dios, a la Pachamama... (2006: 21/01)

LUGO: "Cuando encontré la palabra de Boff y de Gutiérrez, entre otros, percibí claramente que era esa la Iglesia destinada a nutrir de esperanza activa a seres

${ }^{5}$ A decir verdad, las dos frases, acompañadas de una explicación español y por eso mismo dirigidas a un público extranjero, se deben a un contexto especialmente favorable en los discursos indigenistas de Morales se encuentran pocas palabras ('Pachamama' en lugar de Madre Tierra, 'k'hara' en lugar de blanco) más que frases enteras en quechua y aymara. En efecto, la resistencia del actual presidente de Bolivia al uso del idioma aymara en el debate público le ha sido de vez en cuando reprochado. Entre las críticas sobresale la de Felipe Quispe, candidato a primer senador de la agrupación ciudadana Gente y otrora líder del Movimiento Indígena Pachakuti, que le ha recordado que la nueva Constitución del estado obliga a los bolivianos hablar idiomas nativos (La Patria 2009). 


\section{Altre Modernità / Otras Modernidades / Autres Modernités / Other Modernities}

Università degli Studi di Milano - Facoltà di Lettere e Filosofia

Dipartimento di Scienze del Linguaggio e Letterature Straniere Comparate - Sezione di Studi Culturali

hermanos y humanos... por ellos estoy aquí y por esto mismo este laico

eternamente agradecido con su Madre Iglesia permanecerá aferrado a su fe solidaria hasta el fin de su humilde historia" $(2008,15 / 08)$

\section{CORREA: "consagraré todo mi esfuerzo, con la ayuda de Dios" (2007, 15/01)}

Nota: todos los discursos castristas reflejan una actitud laica y respetuosa hacia las religiones, inclusive la católica, sin alusiones a creencias personales. Ni siquiera en ocasión del encuentro con Juan Pablo II y a pesar de mencionar su formación en escuelas de jesuitas, Fidel saldrá de esta línea. Esto no impide que el comandante en jefe se declare "hombre de fe", pero sólo en la revolución y en los ideales marxistas. Chávez, en cambio, es un católico de fe popular, devoto del escapulario de la Virgen del Carmen, y en sus discursos hace abundante uso de términos y metáforas religiosas, que la Iglesia venezolana no interpreta como sinceras ${ }^{6}$. Correa (que se define cristiano de izquierda) y Lula ${ }^{7}$ son más sobrios y prudentes en sus declaraciones de fe. Y la misma actitud de respetuosa sobriedad se aprecia en los discursos de Lugo, a pesar de su complejo compromiso con la Iglesia Católica por su pasado de obispo y su vinculación con la Teología de la Liberación. Morales, a través de la referencia a la Pachamama, a la Madre Tierra, introduce un elemento nuevo en sus discursos, coherentemente con su línea política en defensa de los derechos indígenas y con su empeño en promulgar una nueva Constitución aprobada por el referendum de $2009^{8}$, como bien explica Walter Mignolo9.

6 "'Eso es absurdo. Chávez no es católico. El es lo que le conviene en el momento. Chávez está con un evangélico, y es evangélico. Cuando visitó a Muammar Gaddafi le dijo: Alá es grande; fue a China y entonces alabó a Mao Tse-tung' ... Según el Cardenal Castillo Lara, Chávez sigue un principio del materialismo práctico, donde la verdad es lo que en un determinado momento conviene a la causa del proletariado". Según el Cardenal Castillo Lara, Chávez sigue un principio del materialismo práctico, donde la verdad es lo que en un determinado momento conviene a la causa del proletariado" (2005).

7 "Eu sou católico, mas muito mais do que ser católico, eu sempre tive uma relação muito forte com a Igreja Católica, sobretudo com os movimentos sociais ligados a ela" (2007).

8 En tiempos inmemoriales se erigieron montañas, se desplazaron ríos, se formaron lagos. Nuestra amazonia, nuestro chaco, nuestro altiplano y nuestros llanos y valles se cubrieron de verdores y flores. Poblamos esta sagrada Madre Tierra con rostros diferentes, y comprendimos desde entonces la pluralidad vigente de todas las cosas y nuestra diversidad como seres y culturas. Así conformamos nuestros pueblos, y jamás comprendimos el racismo hasta que lo sufrimos desde los funestos tiempos de la colonia... Cumpliendo el mandato de nuestros pueblos, con la fortaleza de nuestra Pachamama y gracias a Dios, refundamos Bolivia" (Preámbulo a la Constitución 2009).

9 "El discurso de Evo Morales, también reproducido en varias entrevistas, es básicamente el siguiente: los recursos naturales no se pueden privatizar porque son propiedad del pueblo y el pueblo es la voz de Dios. Este principio, así transmitido en las entrevistas, tiene una densidad irreductible al discurso monocorde del periodismo y de libros que divulgan los pros y los contras de la globalización. En primer lugar, la invocación a Dios es, por un lado, una concesión al discurso cristiano -que está en el fondo de liberales y neoliberales a pesar del secularismo y por otro, una invocación directa a la Pachamama, a la concepción teológica de los aymaras. En la cosmología aymara -distinta de la transformación cosmológica que introduce Francis Bacon en 1610 al hacer de la Naturaleza un ente exterior al Hombre (sic) y que debe ser dominada por el Hombre- no hay distinción entre Naturaleza y 


\section{Altre Modernità / Otras Modernidades / Autres Modernités / Other Modernities}

Università degli Studi di Milano - Facoltà di Lettere e Filosofia

Dipartimento di Scienze del Linguaggio e Letterature Straniere Comparate - Sezione di Studi Culturali

\section{CONCLUSIONES}

En calidad de miembros del "Groupe de Recherche sur la parole" de la Universidad de Paris 8, Dorna y Argentin ya subrayaban en 1993 la utilidad de estudiar, en el ámbito del discurso político, la interacción entre los aspectos verbales y aquellos propios de la gestualidad, ya que "todas estas actividades conductuales asociadas al contenido de la palabra obedecen a un objetivo común: dar un sentido al discurso y obtener la adhesión de los interlocutores" (1993: 62). Sólo Dorna, en otro ensayo subrayaba que, siendo la política también "un simulacro de combate" (1993: 118), con la utilización de los medios masivos de comunicación el nuevo discurso se iba a plegar a las exigencias del espectáculo, ya que "la apariencia cuenta más que la esencia, la imagen más que la idea, la forma más que el contenido, las fórmulas retóricas están destinada a producir impacto y (con)vencer acallando el discurso del adversario" (1993: 119). En este sentido, la gestualidad, presente en cualquier discurso, adquiere en un contexto mediatizado una función persuasiva de especial relevancia, que lejos de substituirse a la figuras retóricas clásicas, las acompaña. En su trabajo, Dorna reportaba los resultados del análisis del debate entre dos políticos franceses afirmando que el impacto de las figuras retóricas era estadísticamente significativo ${ }^{10}$. Hubiera resultado muy útil e interesante (a la vez que imposible por razones de espacio y de tiempo) acercarme a la filosofía retórica de nuestros líderes latinoamericanos a través de la metodología de Dorna, así como analizar un muestra de sus discursos según la taxonomía propuesta por Argentin (1989) a través del modelo M.A.P. ${ }^{11}$ que los psicolinguistas utilizan para entrenar a los oradores.

En un discurso político bien logrado, según la experiencia de Dorna, deberían eliminarse los gestos adaptadores, disminuir los punteadores y mantenerse los metafóricos. Para cualquier persona que haya asistido al "espectáculo" de un discurso de Fidel resulta fácil afirmar que él fue un maestro en el uso de los gestos metafóricos

Hombre, y menos aún se concibe la Naturaleza como un ente a ser explotado. La Naturaleza en el vocabulario indígena es "la tierra". En Bolivia la palabra tierra implica mucho más que una superficie que se puede medir y vender por metros cuadrados. Está cargada de sentidos que tocan al poder - a la matriz colonial del poder -, al racismo, a la violencia, al sufrimiento y a la explotación, a luchas de descolonización y esperanzas de libertad, de terminar con la dominación y la explotación constante. En esta constelación semántica de la cosmología indígena, los hidrocarburos, como el agua, no son mercancías" (Mignolo 2006).

10 A través de dos cuadros, Dorna muestra en términos cuantitativos la existencia de una diferencia importante entre los dos oradores y compara las diez figuras más utilizadas por uno y otro de los protagonistas, es decir Chirac y Fabius (1993: 122-123). A título de curiosidad, quien resultó más "retórico" en la investigación de Dorna (Chirac), fue quien ganó las elecciones.

${ }^{11}$ Los gestos Metafóricos (M) son aquellos que se presentan como una analogía sustitutiva de las palabras que designan la acción. Los gestos de tipo Adaptador (A) son los que traducen una adaptación - involuntaria - del orador al pronunciar el discurso y en relación a la situación oratoria. Finalmente, los gestos de tipo Punteador $(\mathrm{P})$ permiten marcar y resaltar las palabras. 


\section{Altre Modernità / Otras Modernidades / Autres Modernités / Other Modernities}

Università degli Studi di Milano - Facoltà di Lettere e Filosofia

Dipartimento di Scienze del Linguaggio e Letterature Straniere Comparate - Sezione di Studi Culturali

(¡cuantas imágenes evocaba con su índice y cuantas palabras nos transmitía con sus silencios y sus miradas!). Su principal admirador, que es sin duda Chávez, se desborda hacia una gestualidad exagerada y enfática, acompañada por cierta rigidez militar del cuerpo. Su indumentaria talvez refleje esta oscilación entre lo carnavalesco y lo cuaresmal: de vez en cuando uniformado de verde olivo con boina roja, a veces con camisa colorada, en ocasiones internacionales y más solemnes en saco y corbata chillona. El líder venezolano es carismático y transmite su energía a través del movimiento de las manos, que bien se conjuga con los detalles rojo sangre de sus accesorios, porque, como escribe Dorna a propósito del político populista: "L'énergie étant contagieuse, le charisme joue un rôle antidépressif. Car c'est le jeu de la séduction, du contact direct et chaleureux qui permet de mobiliser et d'organiser un peuple résigné mais en colère" (2003: 9).

La fuerza persuasiva de Lula, en cambio, se encuentra exactamente en la pragmaticidad y sencillez de sus discursos, breves y bien argumentados. Aunque mucho se deba - según las malas lenguas - a la asesoría del ministro Luiz Dulci, vocero del gobierno a nivel nacional e internacional, es indudable que el líder brasileño tiene su estilo de sindicalista entrenado, sobre todo cuando improvisa y habla "a língua do povo", con la gestualidad moderada de quien está acostumbrado a negociar con la contraparte más que a encantar a las masas. Será por esto, también, que siempre se pone un traje formal, de cierta elegancia dominguera, que lleva casi que con espíritu de servicio y sin vanidad.

Más suave en los modales y austero en la gestualidad se presenta a los ojos públicos Fernando Lugo. Su ropa coherentemente informal (pantalones y camisas, sandalias, colores casi siempre oscuros, nunca corbata) sigue siendo la de un cura obrero de los años 70 y por eso mismo adquiere valor simbólico y transmite un mensaje extraverbal de gran legibilidad. De la misma manera, resultan fuertemente simbólicas las tradicionales chompas de vicuña de Evo Morales y las refinadas camisas otovaleñas de Rafael Correa, a través de las cuales el cuerpo del líder se hace representación del entero sujeto indígeno.

Sin embargo, si Morales - orador algo tímido - ha elaborado éxitosamente su imagen a través del uso simbólico de la indumentaria y de la representación pública de su cuerpo aymara, protagonizando ceremonias espectaculares como la de Tihuanaco, Correa se mantiene bien aferrado a las palabras, a la fuerza persuasiva de un discurso sabiamente estructurado según la tradición oratoria de los jesuitas (¿acaso el actual presidente e de Ecuador no se licenció en la Universidad Católica de Santiago de Quito y no consiguió su master en economía en la Universidad Católica de Lovanio?). A pesar de no ser político de carrera ni sindicalista y de llevar pocos años en el poder, Correa es un comunicador seguro y directo, aunque muy emotivo, como se puede apreciar en su discurso del 19 de octubre de 2009. Un evento, desde el punto de vista retórico (y político) de gran interés, que no ha tenido el eco mediático que me hubiera imaginado: Correa, en vez de negar el problema o regañar a la prensa, decide hablar públicamente sobre un conflicto privado (las fuertes tensiones con su hermano mayor) con implicaciones públicas, reiterando la lucha a la corrupción de su gobierno 


\section{Altre Modernità / Otras Modernidades / Autres Modernités / Other Modernities}

Università degli Studi di Milano - Facoltà di Lettere e Filosofia

Dipartimento di Scienze del Linguaggio e Letterature Straniere Comparate - Sezione di Studi Culturali

y proponiendo la institución de comités de defensa de la revolución ciudadana, según el modelo cubano. La voz del líder, naturalmente tenoril y suave, es ronca, su gestualidad se ha vuelto mecánica, con muchos gestos de tipo A (adaptadores). Sin embargo, Correa sale por lo menos bien de prueba tan delicada, gracias también al empleo - creo yo - de dos elementos extraverbales de gran potencia simbólica: la presencia, detrás del orador vestido de negro, como telón de fondo coloreado, de un grupo de "figurantes" indígenas ataviados con sus traje tradicionales y - dulcis in fundo - la materialización de un grupo musical tradicional que interpreta Hasta siempre de Carlos Puebla, pieza que no sólo subraya un vínculo ideológico entre la revolución cubana y la revolución ciudadana de Correa, sino que sugiere un acercamiento del orador ecuatoriano a la figura del Che.

A la luz de todas estas consideraciones, creo haber demostrado que a la lenta construcción de un imaginario colectivo que favorezca la participación a un proyecto común de sujetos que se hallan en distintos lugares del continente latinoamericano, corresponden estrategias comunicativas adecuadas y de vez en cuando sorpresivas. Es el caso emblemático del estilo discursivo de Chávez, donde "lo oral penetra el discurso anquilosado, formal, acartonado del aparato burocrático" (Narvaja de Arnoux 2009). Satisfaciendo las exigencias del espectáculo mediático y al mismo tiempo cuidando que las palabras actúen ideológicamente, el discurso latinoamericano, profundamente marcado por la lección ética y política de Fidel Castro pero autónomo desde el punto de vista estilístico e ideológico, defiende la democracia radical y diseña perspectivas de cambios sociales según el punto de vista y la elaboración dialéctica del nuevo sujeto nativo silenciado durante siglos.

\section{BIBLIOGRAFÍA}

Argentin, G., 1989, Quand faire c'est dire..., Liège-Bruxelles, Mardaga.

Cárdenas G., 1996-1997, “El discurso político-propagandístico en el español de Cuba", Anuario L/L (Estudios lingüísticos), La Habana, Instituto de Literatura y lingüística, n. 27/28, pp. 12-22.

Chilton P. y C. Schäffner, 2002, Analytic approaches to political discourse, University of East Anglia / Aston University.

Coseriu, E., 1977, Principios de semántica estructural, Madrid, Gredos.

Dorna A., 1993, "Estudios sobre el discurso político: el papel persuasivo de las figuras retóricas y de la gestualidad", Psicología Política n. 6, mayo, 117-128, <http://www.uv.es/garzon/psicologia\%20politica/N6-6.pdf> (21/02/2010).

Dorna A. y G. Argentin, 1993, "Impacto persuasivo del gesto en el discurso político: una experiencia del consejo (asesoría) y de laboratorio", Revista 


\section{Altre Modernità / Otras Modernidades / Autres Modernités / Other Modernities}

Università degli Studi di Milano - Facoltà di Lettere e Filosofia Dipartimento di Scienze del Linguaggio e Letterature Straniere Comparate - Sezione di Studi Culturali

Latinoamericana de Psicología, año/vol. 25, 1, Bogotá, Colombia, pp. 61-72, <http://redalyc.uaemex.mx/redalyc/src/inicio/ArtPdfRed.jsp?iCve=80525105> (21/02/2010).

Dorna, A., 2003, "Faut-il avoir peur du populisme?", Le Monde diplomatique, novembre 2003, pp. 8-9, <http://www.monde-diplomatique.fr/2003/11/DORNA/10680> (21/02/2010).

Mignolo W., 2006, "Giro a la izquierda o giro descolonial? Evo Morales en Bolivia", Revista del Sur, n. 164, marzo/abril, <http://www.redtercermundo.org.uy/revista_del_sur/texto_completo.php?id=2990> (25/02/2010).

Narvaja de Arnoux E., 2008, El discurso latinoamericanista de Hugo Chávez, Buenos Aires, Biblos.

Machado J., 2010, "Lula e a língua do povo", <http://www.ciberduvidas.com/ lusofonias.php?rid=97> (19/02/2010).

Verón E., 1987, El Discurso político: lenguajes y acontecimientos, Buenos Aires, Hachette.

Van Dijk T., 1998, Ideología. Un enfoque multidisciplinario, Madrid, Gedisa.

2000, Estudios del discurso: introducción multidisciplinaria, 2 vols., Madrid, Gedisa.

1996, "Análisis del discurso ideológico (1996/1995)", Versión (México D.F.), 6, pp. 15-43.

1997, "Discurso, cognición y sociedad" (1997), en Signos 8 (22), 1997, 66-74.

2005, "Discurso, conocimiento e ideología", Cuadernos de Información y Comunicación, 10, pp. 285-318.

1999, "Un estudio lingüístico de la ideología", en Giovanni Parodi Sweis (Ed.), Discurso, cognición y Educación. Ensayos en Honor a Luis A. Gómez Macker, Chile, Ediciones Universitarias de Valparaíso de la Universidad Católica de Valparaiso, pp. 27-42.

1999, “El análisis crítico del discurso (1999/2001), Anthropos (Barcelona), 186, septiembre-octubre, 1999, pp. 23-36.

2005, "Ideología y análisis del discurso" (2005/2006), Utopía y Praxis Latinoamericana (Universidad del Zulia, Maracaibo, Venezuela), 10, n 29 (AbrilJunio), pp. 9-36. 


\section{Altre Modernità / Otras Modernidades / Autres Modernités / Other Modernities}

Università degli Studi di Milano - Facoltà di Lettere e Filosofia Dipartimento di Scienze del Linguaggio e Letterature Straniere Comparate - Sezione di Studi Culturali

1993, "Modelos en la memoria. El papel de las representaciones de la situación en el procesamiento del discurso", Revista Latina de Pensamiento y Lenguaje, 2 (1), Invierno, pp. 39-55.

2005, "Política, ideología y discurso", en Quórum Académico (Universidad de Zulia, Maracaibo, Venezuela), 2 (2), pp. 15-47.

2009, "El Malku desafía a Evo Morales a debatir en aymara", La Patria, 9 de octubre, <http://educamposv.lacoctelera.net/post/2009/10/09/el-mallku-desafiaevo-morales-debatir-aymara> (21/02/2010).

2005, "Cardenal Castillo Lara asegura que Chávez no es católico", What the cardinal believe, 23 de octubre, <http://www.cardinalrating.com/cardinal_140_article_1890.htm>(21/02/2010).

DISCURSOS

\section{Fidel Castro}

1959, "Discurso pronunciado por el doctor Fidel Castro Ruz, en el Parque Céspedes, de Santiago de Cuba, el 1ro de enero de 1959", <http://www.cuba.cu/gobierno/discursos/1959/esp/f010159e.html> (15/02/2010)

1961, "Discurso pronunciado por el Comandante Fidel Castro Ruz, Primer Ministro del Gobierno Revolucionario, en el Parque Central de Melena del Sur, primer territorio municipal libre de analfabetismo, el 8 de noviembre", <http://www.cuba.cu/gobierno/discursos/1961/esp/f081161e.html> (15/02/2010)

1961, "Discurso pronunciado por Fidel Castro Ruz, Presidente de la República de Cuba, en la concentración celebrada en la Plaza de la Revolución 'José Martí', para proclamar a Cuba Territorio Libre de Analfabetismo, el 22 de diciembre", <http://www.cuba.cu/gobierno/discursos/1961/esp/f221261e.html> (21/02/2010).

1961, "Discurso pronunciado por el Comandante Fidel Castro Ruz, Primer Ministro del Gobierno Revolucionario, en el acto celebrado en honor de las madres de las jóvenes campesinas que se encontraban estudiando en La Habana, efectuado en la Ciudad Deportiva, el 14 mayo", <http://www.cuba.cu/gobierno/discursos/1961/esp/f140506e.html> (21/02/2010).

1962, “Discurso pronunciado por el comandante Fidel Castro Ruz, primer ministro del gobierno revolucionario, en el acto de homenaje a los mártires del asalto al Palacio Presidencial, en la escalinata de la Universidad de La Habana, el 13 de 


\section{Altre Modernità / Otras Modernidades / Autres Modernités / Other Modernities}

Università degli Studi di Milano - Facoltà di Lettere e Filosofia Dipartimento di Scienze del Linguaggio e Letterature Straniere Comparate - Sezione di Studi Culturali

marzo", <http://www.cuba.cu/gobierno/discursos/1962/esp/f130362e.html> (21/02/2010).

1976, "Cuando un pueblo enérgico y viril llora, la injusticia tiembla. Discurso en el acto de despedida del duelo de las víctimas del avión de Cubana de Aviación destruido el 6 de octubre de 1976 en pleno vuelo, pronunciado en la Plaza de la Revolución el 15 de octubre", La Habana, Editorial de Ciencias Sociales.

1999, "Discurso en la sesión de clausura de la VIII cumbre iberoamericana efctuada en la sala Douro, del centro de conferencias del edificio de la Aduana Vieja, Oporto, Portugal, 18 de octubre", En la unidad está el futuro de nuestros pueblos. Cumbres Iberoamericanas, La Habana, Editora Política, pp. 101-115.

2001, "Patria y Humanidad se han unido inseparablemente, por la historia y para siempre, en la mente y el corazón del pueblo. Discurso pronunciado por el presidente cubano Fidel Castro Ruz, con motivo del 40 aniversario de los combates de Girón y de la primera gran derrota del imperialismo en América, efectuado en Playa Girón, el 19 de abril", <http://www.cubavision.cubaweb.cu/discursos_detalles.asp?ID=132> (18/02/2010)

2005, "Intervención Especial del Presidente de la República de Cuba, Fidel Castro Ruz, ante dirigentes del Partido, el Estado, el Gobierno y la Unión de Jóvenes Comunistas, representantes de las organizaciones de masa, oficiales, combatientes de las FAR y el MININT, familiares y víctimas sobrevivientes de los actos terroristas del imperio en nuestro país, en el Palacio de las Convenciones, el 15 de abril", <http://www.cuba.cu/gobierno/discursos/2005/ esp/f150405e.html> (18/02/2010)

\section{Hugo Chávez}

2001, "Discurso en inauguración de la I Cumbre sobre la Deuda Social y la Integración Latinoamericana, 10 de julio",

<http://www.analitica.com/Bitblio/hchavez/deuda_social.asp> (12/02/2010)

2002 (14/04), "Alocución a la nación al retornar al poder", <http://www.analitica.com/BITBLIO/hchavez/vuelta_al_poder.asp> (10/12/2009).

2002 (13/10) "Discurso ante la marcha popular en respaldo a su gobierno", <http://www.analitica.com/Bitblio/hchavez/marcha20021013.asp> (12/02/2010)

2005 "Discurso del Presidente Chávez en la ONU, 15 de septiembre de 2005", $<$ http://www.profesionalespcm.org/_php/MuestraArticulo2.php?id=4210> (21/02/2010).

2007, “Discurso de Hugo Chávez Frías, Presidente de la República Bolivariana de Venezuela, en el acto de firma de acuerdos entre Venezuela y Cuba, efectuado en el Palacio de las Convenciones, 15 de octubre", <http://www.granma.cubaweb.cu/secciones/alba/int/2integ44.html (18/02/2010) 


\section{Altre Modernità / Otras Modernidades / Autres Modernités / Other Modernities}

Università degli Studi di Milano - Facoltà di Lettere e Filosofia Dipartimento di Scienze del Linguaggio e Letterature Straniere Comparate - Sezione di Studi Culturali

2009, "Discurso íntegro del presidente Chávez ante la 64 Asamblea General de la ONU, 30 de agosto", <http://chamosaurio.com/2009/09/30/la-revolucionnecesaria/> (18/02/2010)

\section{Rafael Correa}

2009, "Discurso de posesión, Quito, 10 de agosto" $<$ http://www.presidencia.gov.ec/pdf/DiscursoPosesion\%2010\%20de\%20agosto_pdf_2009.pdf> (13/02/2010).

2009, "Discurso en la Plaza San Francisco, 17 de octubre" <http://www.youtube.com/watch?v=hd92GRJIR3k> (13/02/2010).

2007, "Los ejes del nuevo gobierno. Discurso completo de la toma de posesión de Rafael Correa como presidente de Ecuador, 15 de enero", $<$ http://www.democraciasur.com/documentos/EcuadorCorreaTomaPresidencial.htm> (13/02/2010).

2007, "Discurso del Presidente de la República, Rafael Correa, en Babahoyo, 15 de septiembre", <http://www.archive.org/details/babahoyorc> (13/02/2010).

\section{Inácio Lula da Silva}

2003, "Discurso de posse, 1 de janeiro", <http://www.fiec.org.br/artigos/temas/discurso_de_posse_dopresidente_Luiz_Inacio _Lula_da_Silva.htm> (16/02/2010)

2003, "Discurso do Presidente na cerimonia da instalação da Secretaria de Promoçao de Politicas de Promoçao da Igualdade Racial, Palácio de Planalto, 21 de março", <http://www.pt.org.br/portalpt/secretarias/-combate-ao-racismo-14/artigos133/discurso-do-presidente-na-criacao-da-seppir-815.html> (16/02/2010)

2006 (25/10), "Discurso da assinatura de Decreto que institui a coleta seletiva nos órgãos federais e anúncio de linha de crédito para catadores de materiais recicláveis, 25 de outubro", http://www.mds.gov.br/arquivos/discurso-do-presidenteda-republica-luiz-inacio-lula-da-silva-na-cerimonia-de-assinatura-de-decreto-queinstitui-a-coleta-seletiva (18/02/2010)

2007, "Entrevista exclusiva concedida ao Sistema de Comunicação Canção Nova, 9 de maio",

<http://www.cancaonova.com/portal/canais/entrevista/entrevistas.php?id=402> (25/02/2010). 


\section{Altre Modernità / Otras Modernidades / Autres Modernités / Other Modernities}

Università degli Studi di Milano - Facoltà di Lettere e Filosofia Dipartimento di Scienze del Linguaggio e Letterature Straniere Comparate - Sezione di Studi Culturali

2009 (02/11), “Discurso do Presidente da República, Luiz Inácio Lula da Silva, na sessão de apresentação da Candidatura Rio 2016 ao Comitê Olímpico Internacional, Copenhague-Dinamarca, 2 de novembro", <http://blog.planalto.gov.br/chegou-ahora-de-acender-a-pira-olimpica-em-um-pais-tropical/ > (18/02/2010).

2009, "Solenidade em que Lula sancionou o projeto Marcha para Jesus, 6 de setembro", <http://26hora.wordpress.com/2009/09/06/discurso-na-integra-senadorcrivella-\%E2\%80\%93-solenidade-em-que-lula-sancionou-projeto-marcha-para-jesus/> (25/02/2010).

2009, "Discurso do Presidente da República, Luiz Inácio Lula da Silva, na cerimônia de abertura da $1^{\text {a }}$ Conferência Nacional de Comunicação (Confecom), Brasília-DF, 14 de dezembro", <http://www.teletime.com.br/arqs/Outro/15061.pdf> (25/02/2010).

\section{Fernando Lugo}

2008, "Discurso completo del presidente paraguayo Fernando Lugo al tomar el mando, 15 de agosto", <http://www.misionesonline.net/paginas/detalle2.php?db= noticias $2007 \& d=119067>(10 / 02 / 2010)$

2008, " Discurso pronunciado por Fernando Lugo, Presidente de Paraguay, Observatorio eclesial, 18 de agosto", <http://www.redescristianas.net/2008/08/18/discurso-pronunciado-por-fernandolugo-presidente-del-paraguay/> (25/02/2010).

2009, "Discurso del presidente Fernando Lugo en acto de entrega de la memoria final de la comision mixta demarcadora de límites entre Bolivia y Uruguay, 27 de abril", <http://www.presidencia.gov.py/v1/?p=8202> (25/02/2010).

2009, "Palabras del Presidente Fernando Lugo, en Día de Gobierno con el pueblo, Bañado Sur, Asunción, 19 de diciembre", <http://www.presidencia.gov.py/v1/?p=7624> (25/02/2010).

2010, "Discurso en la colonia Tembiapora, Departamento Caaguazú, 19 de febrero", <http://www.presidencia.gov.py/v1/?p=12307> (25/02/2010).

\section{Evo Morales}

2006 "Palabras del Presidente electo de Bolivia, Evo Morales Ayma, Tiahuanucu, 21 de enero", Página 12 ("Los discursos de Evo Morales - Especiales del Martes 31 de enero), <www.aporrea.org> (25/02/2010). 


\section{Altre Modernità / Otras Modernidades / Autres Modernités / Other Modernities}

Università degli Studi di Milano - Facoltà di Lettere e Filosofia Dipartimento di Scienze del Linguaggio e Letterature Straniere Comparate - Sezione di Studi Culturali

2006 "Discurso de posesión del Presidente Cnstitucional de Bolivia, Evo Morales Ayma, La Paz, 22 de enero", Página 12 ("Los discursos de Evo Morales - Especiales del Martes 31 de enero"), <www.aporrea.org> (16/11/2010).

2007, "Acto de apertura del II Foro Humanista Latinoamericano, La Paz, 6 de noviembre", $<$ http://www.forohumanistalatinoamericano.org/discurso-de-evomorales/ > (25/02/2010).

2009, Nueva Constitución Política del Estado de Bolivia, $<$ http://www.ernestojustiniano.org/200810/nueva-constitucion-politica-del-estadode-bolivia> (25/02/2010).

Irina Bajini es profesor agregado e investigadora de literatura hispanoamericana en la Universidad degli Studi de Milán. Además de traductora y editora, es especialista de teatro musical ibérico y de temas cubanos y peruanos. Recientemente ha extendido sus intereses a las relaciones literarias entre Italia y Latinoamérica y a las expresiones culturales afroiberoamericanas.

irina.bajini@unimi.it 